\title{
Basic Endovascular Technique for Aneurysm Coiling
}

\author{
Harsan
}

\subsection{Introduction}

Aneurysm coiling is a method to exclude the aneurysm from circulation. If the aneurysm can be excluded from the circulation, the thrombosis process will be initiated within the aneurysm, and lately it is hoped that there will be an endothelialization on the neck of the aneurysm.

This method is getting more popular and preferred by the patient as can be seen by the data from Lin $\mathrm{N}$ et al. [1] The number of patients with non-ruptured aneurysm that underwent coiling is increased from $20.6 \%$ in period before 2002 to $61.7 \%$ in period 2002-2007, while the number of patients with ruptured aneurysm is increased from $9.3 \%$ in period before 2002 to $42 \%$ in period 2002-2007.

\subsection{Indication}

According to the Guidelines for the Management of Aneurysmal Subarachnoid Hemorrhage [2] and Guidelines for the Management of Patients with Unruptured Intracranial Aneurysm [3], both clipping and coiling are effective treatment for aneurysm and considered for treatment. In rup-

\footnotetext{
Harsan

Department of Neurosurgery, Faculty of Medicine Universitas Pelita Harapan (UPH), Neuroscience Centre Siloam Hospital Lippo Village,

Tangerang, Indonesia
}

tured case, coiling is indicated for elderly patient, patient in poor clinical condition and in those with aneurysm in the basilar apex.

\subsection{Technical Aspect}

There are some steps to follow to get a successful embolization of an aneurysm; these are preparation, vascular access phase, and intervention phase [4].

\subsubsection{Preparation}

This step is preparation of the patient and equipment that will be used in the procedures. Patient's preparation includes clinical/laboratory examination, neurologic examination, and radiologic/ imaging examination.

In clinical examination, doctors have to check the general condition and vital sign of the patient; this condition determines the choice of anesthesia method during the coiling procedures. The main important laboratory tests are coagulation state and renal function study. Other clinical examination is neurologic state, especially if there is a focal neurologic sign.

After doing clinical study of the patient, available radiologic study had to be studied carefully, especially the exact location of the aneurysm and its correlation with the parent artery. 
Before the treatment, the surgeon should start to prepare the tools and equipment for doing the embolization. A certain case requires special instrument such as balloon or stent, for balloonor stent-assisted coiling.

There are several basic tools and equipment that need to be prepared prior to embolization, such as femoral puncture set; femoral (angiography) sheath; pressure bag (three to four sets); RHV (rotating hemostatic valve); three-way connector; guiding catheter; guidewire; microcatheter; microguidewire; coil (with its coil detacher), according to the size of the aneurysm; balloon; and stent. When all of the equipment is ready, the procedures can be started.

\subsubsection{Vascular Access Phase}

For coiling an aneurysm, the patient is usually in general anesthesia. After patient is anesthetized and positioned, the procedure is started by setting the pressurized flushing to give continuous irrigation to the catheter system.

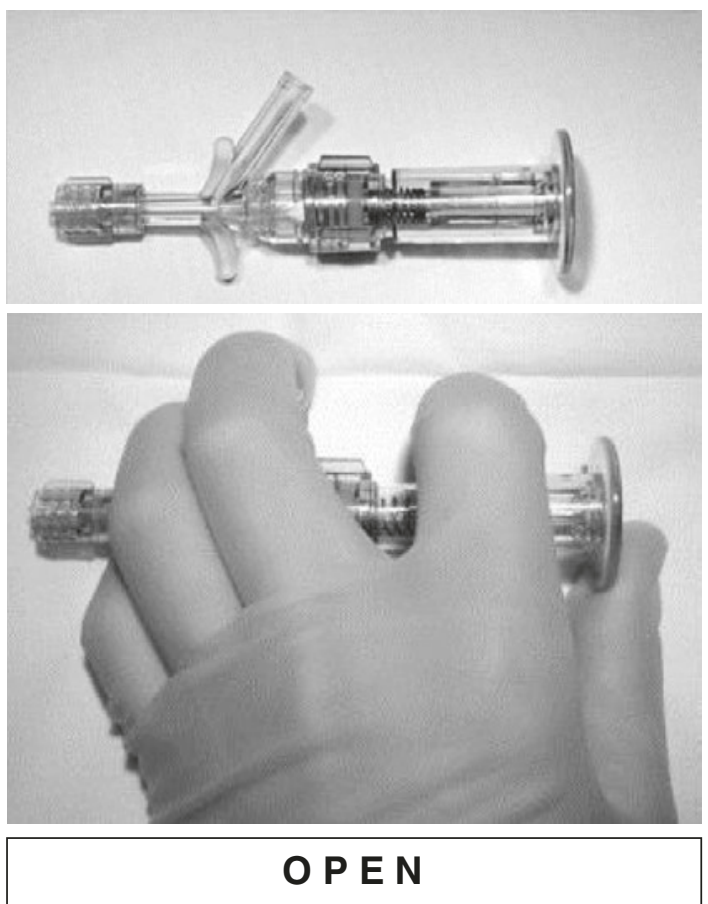

Preferred vascular access is right common femoral artery. The Seldinger technique was used to cannulate femoral artery and followed by placing 6 Fr femoral sheath. Then, angiography is performed to get newest image of the aneurysm, including 3D rotation angiography. This 3D image will guide interventionist to select the best projection to see the correlation of the aneurysm with parent artery.

Once the working projection is selected, the vascular access is continued by inserting $6 \mathrm{Fr}$ guiding catheter with RHV (rotating hemostatic valve) on its proximal that allow continuous pressure irrigation (Fig. 10.1).

The rotating hemostatic valve is a specific "three-way" with controlled valve on its proximal side which prevents leakage of blood or fluid irrigation but can be opened when needed to insert device (like guidewire or microcatheter). The RHV should be set up with the threeway connector, the fluid irrigation, and the contrast flushing during the treatment (Figs. 10.2 and 10.3).

The guiding catheter advances to the location of aneurysm as close as possible to the aneurysm
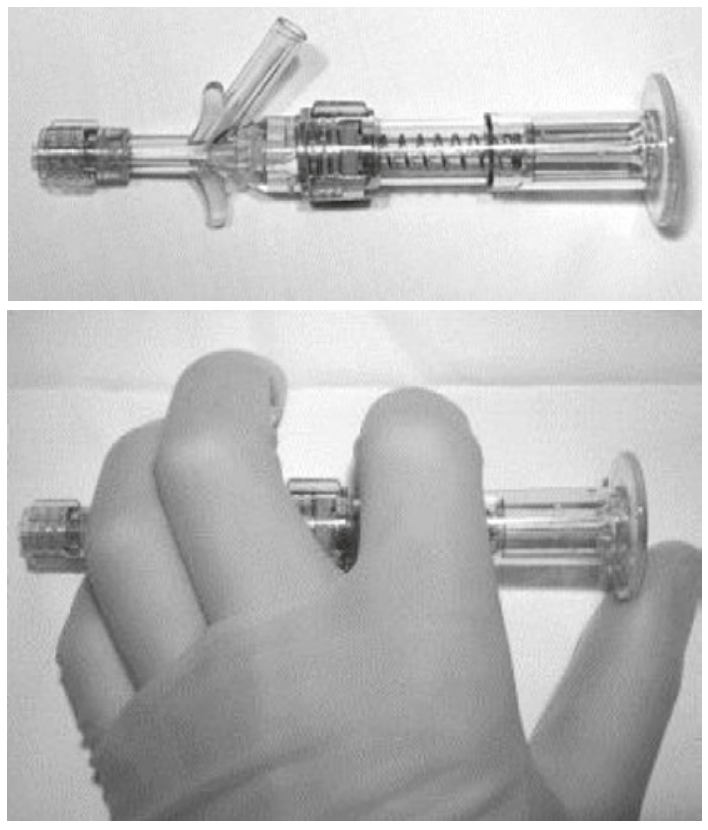

CLOSE

Fig. 10.1 The rotating hemostatic valve should be checked prior to the treatment 


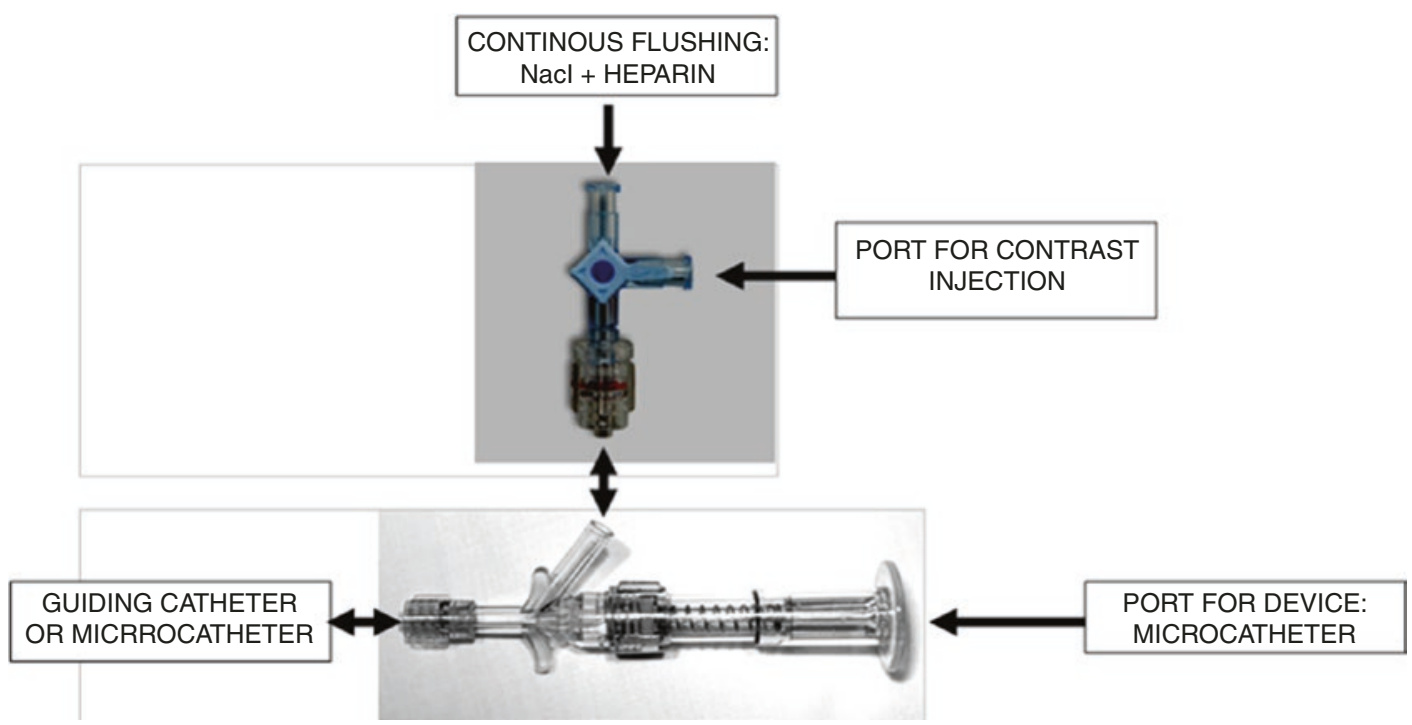

Fig. 10.2 The three-way connector is placed at the RHV side to allow the heparin flushing and contrast injection during the treatment. The microcatheter is inserted through the "port for device"

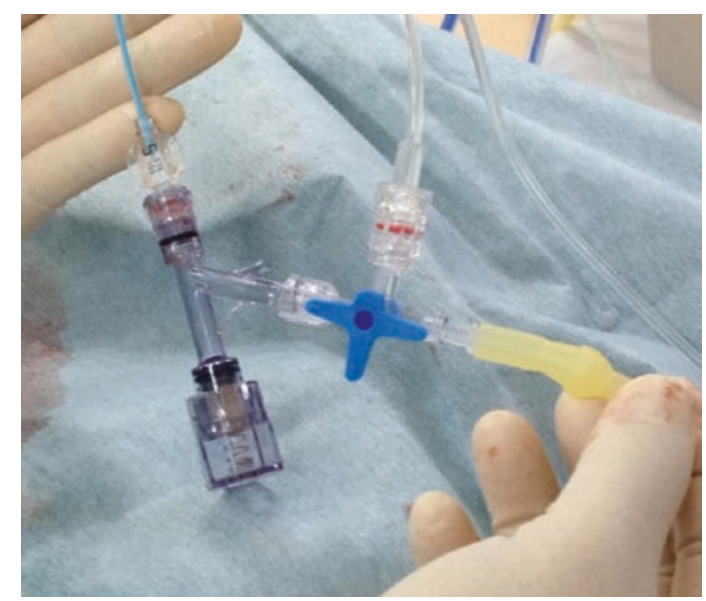

Fig. 10.3 Any device for endovascular is inserted to the catheter/guiding catheter through Y-connector. Three-way is connected to Y-connector to give continuous flushing and contrast injection

but stays extracranial. In the meanwhile, the microcatheter and microguidewire are prepared. The microcatheter can be shaped with the shaping mandrel and heated with steam, while microguidewire is shaped with blunt needle (Fig. 10.4).

The rotating hemostatic valve was put on the proximal part of the microcatheter to give

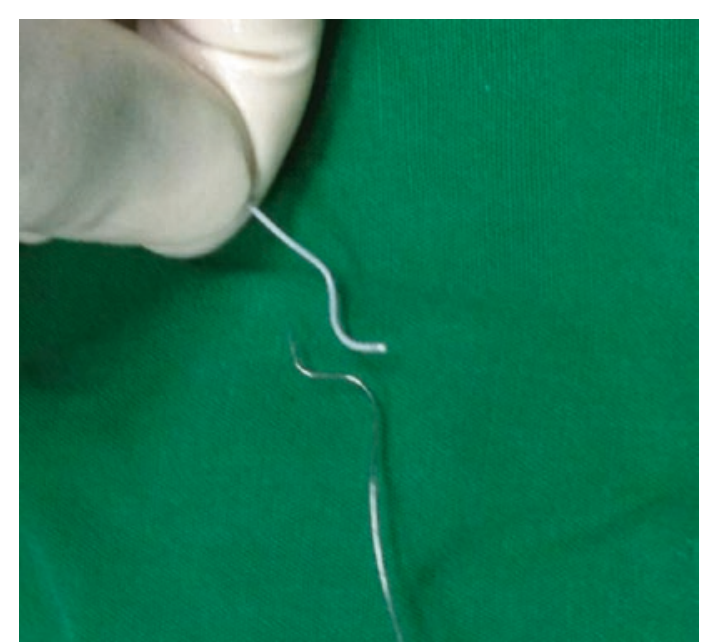

Fig. 10.4 The microcatheter is shaped

continuous irrigation with heparinized saline. Microguidewire was inserted to the microcatheter through RHV. Microcatheter and microguidewire are then inserted to the guiding catheter through the RHV attached on the proximal end of the guiding catheter (Fig. 10.5). 


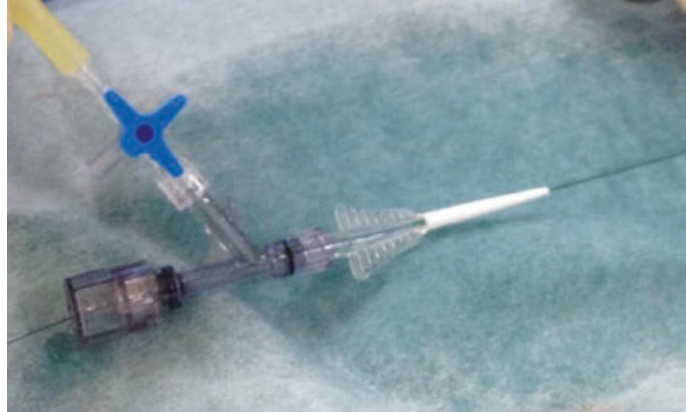

Fig. 10.5 Microguidewire is inserted to the microcatheter through Y-connector. Three-way is connected to Y-connector to give continuous flushing and contrast injection

\subsubsection{Intervention Phase}

After the guiding catheter was placed in desired position, intervention/coiling phase is started. The $\mathrm{X}$-ray tube was adjusted to working position, and angiography to make "road map" imaging is done. Microcatheter and microguidewire is navigated to aneurysm location, guided by road map image. The ideal position of the tip of microcatheter is between one-third and two-thirds on the aneurysm sac.

Heparin 3000-5000 units IV is given once the microcatheter reaches the aneurysm sac in desired position, before starting coiling (5070 units $/ \mathrm{Kg}$ ). Some authors prefer to give this heparin after the first coil is inserted in the aneurysm.

The first coil to deploy is usually a coil with 3D shape and called "framing" coil to cover the entire wall of the aneurysm. Then coiling is continued by "filling" the aneurysm sac with $2 \mathrm{D}$ coil until adequate packing is achieved.
Final angiogram is made to see the final position of coil and condition of parent artery, also the filling of contrast to the aneurysm sac.

\subsection{Case Illustration}

Case 1 (Figs. 10.6, 10.7, and 10.8)Case 2 (Figs. 10.9, 10.10, and 10.11)

During the attempt to do the coiling, it's very important to find the best projection view. It is very individual and necessary to tailor to the location and projection of the aneurysm.

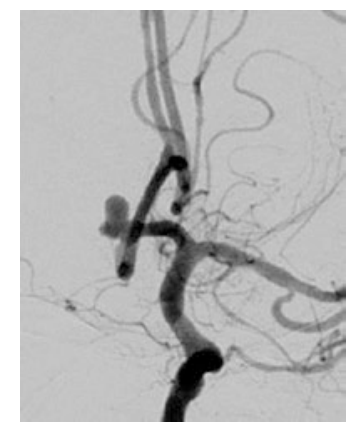

Fig. 10.6 It's a com aneurysm. It's done through the left side. The best projection is RAO 21 CRAN 10

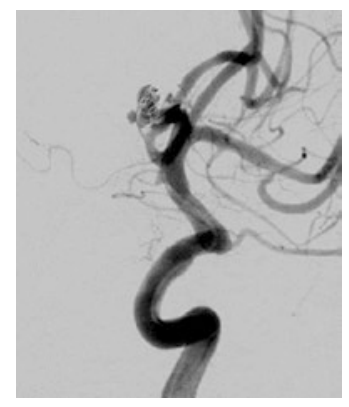

Fig. 10.7 During framing 


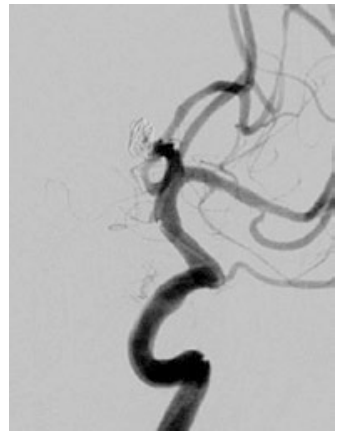

Fig. 10.8 The final angiography after coiling

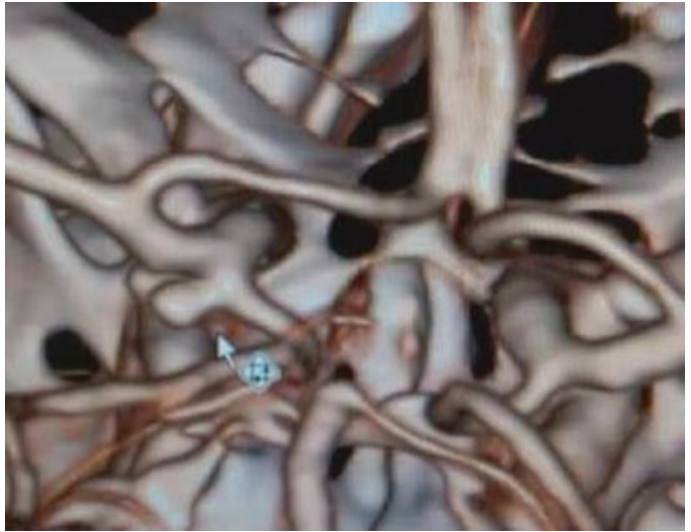

Fig. 10.9 Three-dimensional (3D) CT angiography is showing left IC-P-com aneurysm
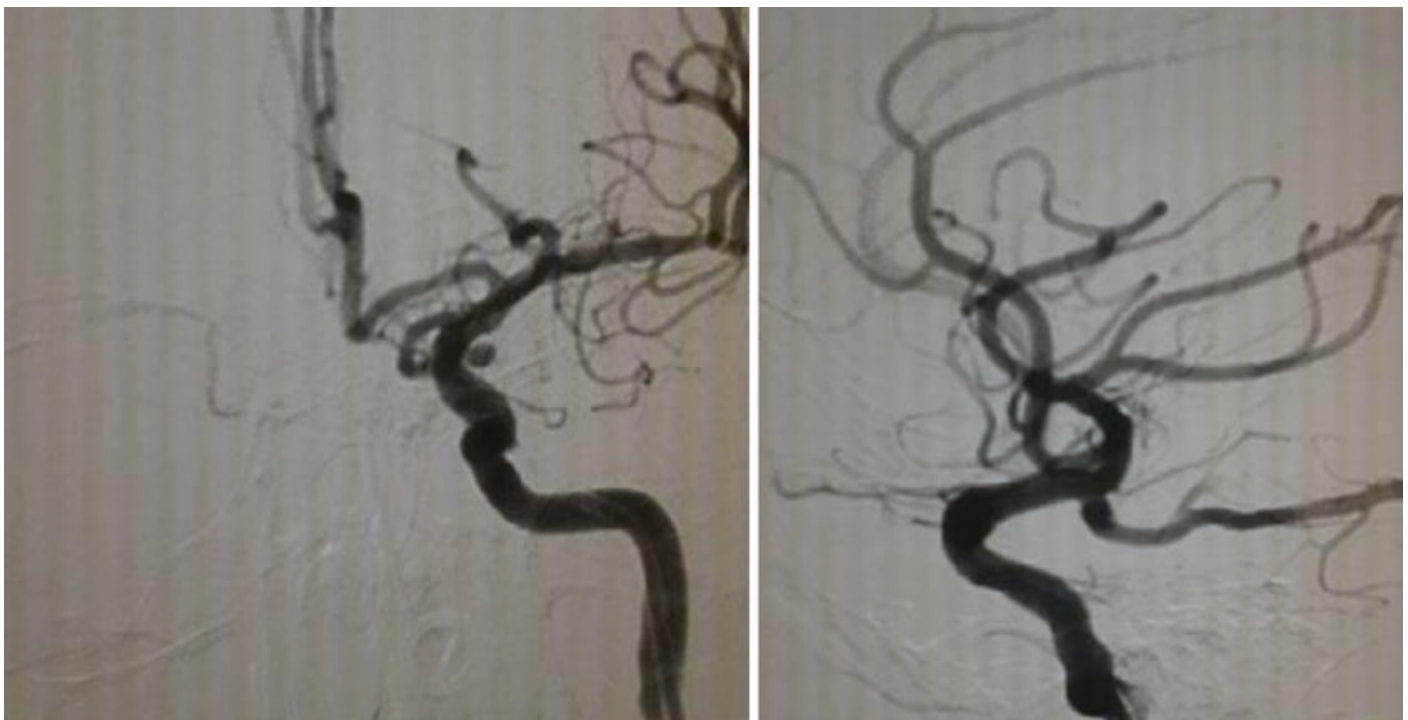

Fig. 10.10 The angiography of left IC, left, AP view, and right, lateral view. Both are not the best projection 

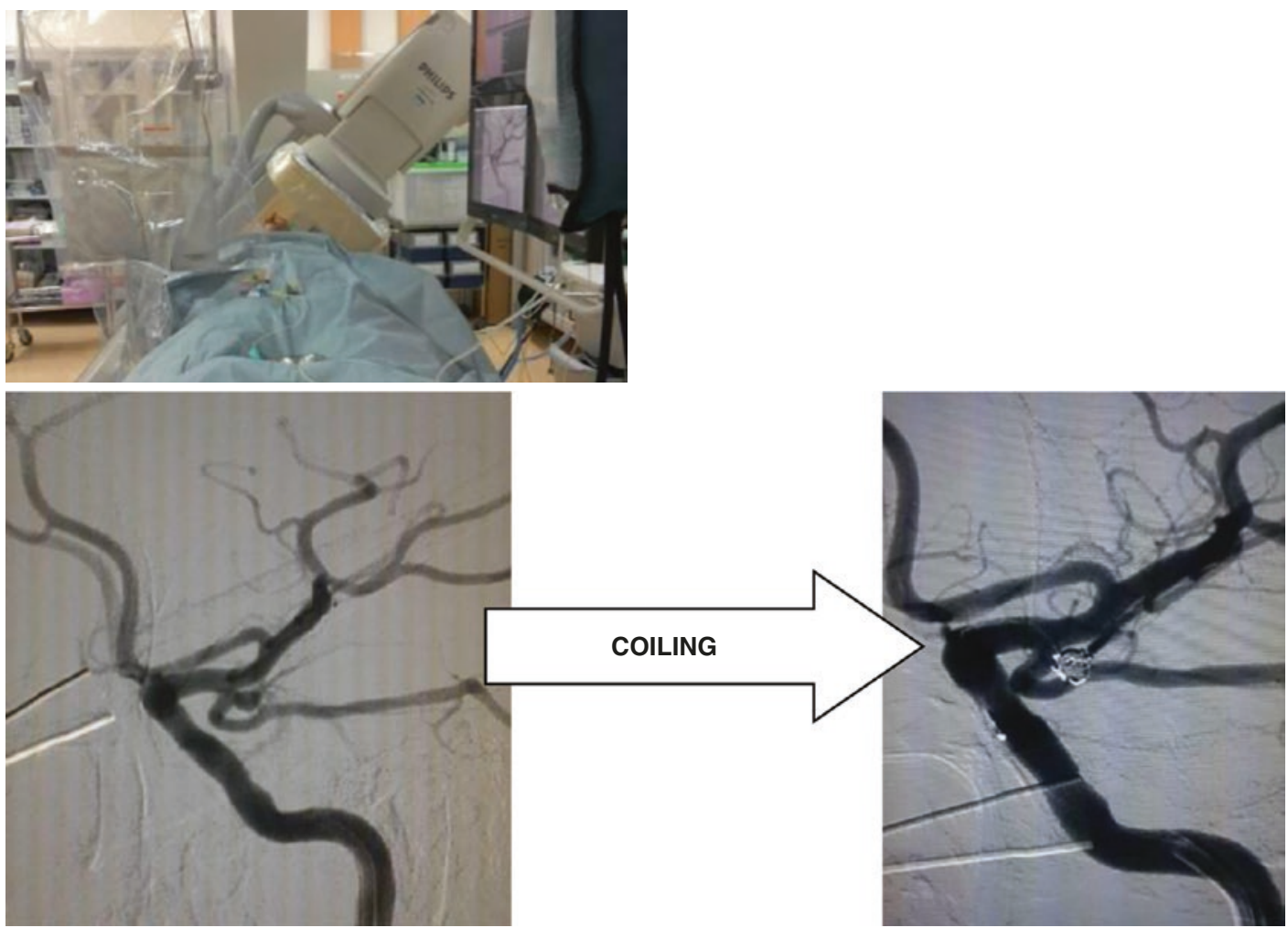

Fig. 10.11 The best projection view is LAO $45^{\circ}$ caudal $5^{\circ}$. Lower: it is showing before and after coiling

\section{References}

1. Lin N, Cahill KS, Frerichs KU, et al. Treatment of ruptured and unruptured cerebral aneurysm in the USA: a paradigm shift. J NeuroIntervent Surg. 2012;4:182-9.

2. Connolly ES, Rabinstein AA, Carhuapoma JR, et al. Guidelines for the management of aneurysmal subarachnoid hemorrhage. Stroke. 2012;43(6):1711-37.
3. Thompson BG, Brown RD, Amin-Hanjani S, et al. Guidelines for the management of patients with unruptured intracranial aneurysms. Stroke. 2015;46:2368-400.

4. Harrigan MR, Deveikis JP. Handbook of cerebrovascular disease and neurointerventional technique. Dordrecht: Humana Press; 2009.

Open Access This chapter is licensed under the terms of the Creative Commons Attribution 4.0 International License (http://creativecommons.org/licenses/by/4.0/), which permits use, sharing, adaptation, distribution and reproduction in any medium or format, as long as you give appropriate credit to the original author(s) and the source, provide a link to the Creative Commons license and indicate if changes were made.

The images or other third party material in this chapter are included in the chapter's Creative Commons license, unless indicated otherwise in a credit line to the material. If material is not included in the chapter's Creative Commons license and your intended use is not permitted by statutory regulation or exceeds the permitted use, you will need to obtain permission directly from the copyright holder.

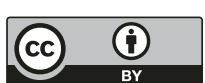

